\title{
Estratégias didáticas para o ensino médio com o uso da flora nativa do Município de Esperantina-PI
}

Teaching strategies for high school with the use of native flora in the Municipality of EsperantinaPI

\section{Estrategias didácticas para la escuela secundaria con el uso de la flora nativa de la Ciudad de} Esperantina-PI

\section{Resumo}

Percebe-se entre os estudantes certo desinteresse pela Botânica, que pode ser causado pela "cegueira botânica", definida como a dificuldade de perceber as plantas ao seu redor. Um dos fatores que contribui para esta situação é o distanciamento entre o que é ensinado na escola e o cotidiano do estudante. Assim, este trabalho buscou analisar o uso da flora nativa, da região em que a comunidade escolar está inserida, como ferramenta didática que desperte esse interesse. Para tal foram aplicadas estratégias diversificadas à estudantes da $2^{\mathrm{a}}$ série do Ensino Médio de uma escola localizada no município de Esperantina-PI. Buscou-se na literatura estudos sobre a vegetação do município, elaborouse estratégias que associassem essas plantas a temas de estudo da Botânica. A coleta de dados foi realizada com aplicação de questionários com abordagem quali-quantitativa, buscando informações sobre conhecimentos prévios acerca da Botânica e a respeito da flora nativa da região. Os resultados obtidos apontam que diversas atividades com o uso da flora aumenta o interesse pela disciplina. Os estudantes afirmaram que passaram a conhecer mais os temas da Botânica de forma geral, além de afirmarem ter mais conhecimentos sobre as plantas nativas da região.

Palavras-chave: Vegetação do Piauí; Aprendizagem; Ensino de botânica.

\begin{abstract}
It is noticed among students a certain lack of interest in Botany, that can be caused by "botanical blindness", defined as the difficulty of perceiving the plants around you. One of the factors that contributes to this situation is the distance between what is taught at school and the student's daily life. Thus, this work sought to analyze the use of native flora, of the region in which the school community is inserted, as a didactic tool that arouses this interest. To this end, diversified strategies were applied to students in the 2nd grade of high school at a school located in the municipality of Esperantina-PI. Studies on the vegetation of the municipality were searched in the literature. strategies were developed to associate these plants with themes of study of Botany. Data collection was performed using questionnaires with a qualitative and quantitative approach, seeking information about previous knowledge about Botany and the native flora of the region. The results obtained show that several activities with the use of flora increase the interest in the discipline. The students stated that they got to know more about Botany more generally, in addition, they stated to have more knowledge about native plants in the region.
\end{abstract}

Keywords: Vegetation of Piauí; Learning; Botany teaching.

\section{Resumen}

Se nota una cierta falta de interés por la Botánica entre los estudiantes, que puede ser causada por la "ceguera botánica", definida como la dificultad para percibir las plantas que les rodean. Uno de los factores que contribuyen a esta situación es la distancia entre lo que se enseña en la escuela y la vida cotidiana del alumno. Así, este trabajo buscó analizar el uso de la flora autóctona de la región donde se inserta la comunidad escolar, como herramienta didáctica para despertar este interés. Para ello, se aplicaron estrategias diversificadas a los alumnos de $2^{\circ}$ de bachillerato de una escuela situada en el municipio de Esperantina-PI. Se buscó en los estudios bibliográficos sobre la vegetación de la ciudad para la selección de las especies que se utilizaron en las estrategias de enseñanza de la asignatura. La recogida de datos se realizó con la aplicación de cuestionarios con enfoque cuali-cuantitativo, buscando 
información sobre los conocimientos previos sobre Botánica y sobre la flora autóctona de la región. Los resultados obtenidos señalan que varias actividades con el uso de la flora aumentaron el interés por el tema. Los alumnos afirmaron que se familiarizaron más con los temas de la Botánica en general, además de afirmar tener más conocimientos sobre las plantas autóctonas de la región.

Palabras clave: Vegetación de Piauí; Aprendizaje; Enseñanza de la botánica.

\section{Introdução}

É indiscutível que as plantas são fundamentais para a existência e manutenção da vida no planeta em razão de diversos processos realizados por estes organismos, como fotossíntese, produção de alimentos, além de outros que mantém vivos os ecossistemas. Entretanto, há uma grande dificuldade no ensino de Botânica no ambiente escolar. Vários trabalhos na literatura científica estão voltados para a discussão dos problemas enfrentados pela prática docente no ensino dessa ciência (Amadeu \& Maciel, 2014; Arrais, Sousa \& Masrua, 2014; Corrêa et al., 2016).

A literatura disponível sobre o ensino de Botânica relata que este vem sendo prejudicado por vários fatores, um desses, é o fenômeno denominado "cegueira botânica" (Wandersee \& Schussler, 2001), em que há dificuldade de notar as plantas presentes no ambiente, bem como sua importância para manutenção da vida e dos ecossistemas que elas sustentam, tornando esse estudo desinteressante e impedindo assim sua compreensão. Além desse, há outros motivos, tais como, a insegurança dos docentes ao trabalhar os conteúdos (Macedo et al., 2012), estudantes e professores manifestam pouco interesse pelos assuntos (Soares, 2020); livros didáticos descontextualizados da realidade do estudante (Freitas, 2012; Arrais, Sousa \& Masrua, 2014), e a relutância dos professores em elaborar metodologias que aproximem o currículo dessa disciplina com a realidade e vivências do estudante, para tornar a aprendizagem mais significativa (Figueiredo, 2009; Ursi et al., 2018).

Todos esses fatores contribuem de forma direta ou indireta para a desmotivação em relação a disciplina. Para facilitar a aprendizagem, o ensino precisa ser mais que conceitual e mecânico, é necessário retomar de alguma forma a relação entre o ser humano e a natureza, já que estes vêm se distanciando (Figueiredo, 2009). Uma forma de reatar essa conexão e minimizar essa "cegueira botânica" é valorizando os conhecimentos que os estudantes possuem, resultado das diversas interações que estes tiveram com o meio ambiente do local em que vivem. Soares (2020), ao fazer um levantamento dos trabalhos apresentados em congressos sobre o ensino de Botânica, observou que o estudo do meio é uma das estratégias mais investigadas como ferramenta para trabalhar esta disciplina. Sendo assim, a contextualização é um requisito fundamental para o aprendizado, pois traz aspectos que compõem a realidade do estudante, tornando o objeto de estudo mais concreto, evitando que o conhecimento seja superficial e facilmente esquecido.

A grande questão aqui, seria como motivar a aprendizagem de Botânica utilizando o fato que o Brasil é um país com uma enorme biodiversidade, em fauna, flora e com vários biomas, e que devido a sua grande extensão territorial, exibe uma vegetação muita rica e diversa de norte a sul (Peixoto, Luz \& Brito, 2016). O Piauí possui área uma de 251.529,2 km² (Cepro, 2004) e apresenta fragmentos dos biomas Cerrado e Caatinga, áreas de transição entre esses biomas, além da zona Costeira (Araújo et al., 2010). A vegetação sofre a influência de outros domínios como o Amazônico, o Planalto Central e do Nordeste e por isso apresenta grande biodiversidade (Farias \& Castro, 2004). O município de Esperantina, situa-se na mesorregião norte do estado do Piauí, na microrregião do Baixo Parnaíba, sua vegetação caracteriza-se como área de transição, apresentando ao norte floresta estacional semidecídua com babaçu, e na porção centro-sul vegetação com característica de áreas de transição com presença de elementos do Cerrado, da Caatinga e floresta estacional (Castro, 1999; Torquato, 2006).

A maioria da população pouco conhece sobre a flora nativa, e esse desconhecimento é resultado da deficiência no ensino de Botânica, já que este não tem sua abordagem baseada no estudo de plantas nativas, nem em metodologias que diminuam a distância entre essas plantas e os estudantes (Silva et al., 2019). Então, como poderia ser utilizada toda essa diversidade para reverter a desmotivação acerca dos assuntos de Botânica? Seria possível aplicar algum método com fim 
educacional? As Diretrizes Curriculares para o Ensino Médio (Brasil, 1998) afirmam que o ensino, dentre outros objetivos, deve ser contextualizado e trazer aspectos da vida cotidiana do estudante com os quais está acostumado. Com isso, ao ser trabalhado elementos da vegetação local, ao qual o estudante está familiarizado, estabelece-se um vínculo entre o mesmo e o que é ensinado e a aprendizagem é construída de forma natural tornando-se expressiva.

É importante que o professor elabore estratégias que motivem para o aprendizado dessa disciplina, realizando aulas mais dinâmicas que estimulem a participação e despertem a curiosidade (Silva, Cândido \& Lima, 2018). Assim, tornando-as mais interessantes e atrativas, consequentemente motivará os estudantes a serem mais ativos e estes aprenderão sobre o ambiente em que vivem. Dessa forma, é possível usufruir de toda essa biodiversidade, apresentando aos estudantes as plantas nativas, conectando a realidade deles com o aprendizado através de metodologias diversificadas.

Com base neste pensamento, este trabalho realizou uma pesquisa com estudantes de uma escola pública estadual do município de Esperantina-PI, cujo objetivo era o de utilizar a flora nativa da região como ferramenta didática, abordando diversos aspectos das plantas por meio de estratégias diferenciadas e desta forma verificar as vantagens da metodologia como facilitadora do ensino, promovendo um melhor aprendizado da Botânica.

\section{Metodologia}

A pesquisa apresenta uma abordagem quali-quantitativa, pois busca a objetividade da análise estatística e a subjetividade da interpretação das informações fornecidas pelos participantes. Para Souza e Kerbauy (2017), essas duas abordagens, qualitativa e quantitativa, são complementares permitindo uma visão global do objeto a ser pesquisado. Para tal utiliza-se questionários com questões fechadas com a abordagem qualitativa ordinal, a fim de realizar os testes estatísticos, e assim aplicar a avaliação quantitativa dos dados, e questões abertas para análise qualitativa do conteúdo (Gerhart, Ramos, Riquinho \& Santos, 2009).

Este estudo foi realizado com 84 estudantes do $2^{\circ}$ ano do ensino médio de uma escola pública estadual do município de Esperantina-PI, divididos em dois grupos, denominados de grupo experimental e grupo controle. O grupo experimental com 45 componentes pertencentes a modalidade de ensino integral participou de todas as atividades propostas neste trabalho e, o grupo controle com 39 estudantes que pertenciam as modalidades regular, e alguns do ensino integral. A coleta de dados foi realizada mediante a aplicação de questionários. Ao grupo experimental foi aplicado questionários pré e pós atividades, e ao grupo controle um único questionário para fins comparativos. O trabalho foi aprovado pelo Comitê de Ética em Pesquisa CONEP e CEP/UESPI; CAAE: 89926518.7.0000.5209 e possui Cadastro no Sistema Nacional de Gestão do Patrimônio Genético e do Conhecimento Tradicional Associado- SISGEN nº A3CE061.

Para a execução do trabalho foram selecionadas previamente 10 espécies (Tabela 1) da vegetação nativa da região, que já haviam sido listadas na literatura que descrevia a flora do município de Esperantina-PI.

O critério de escolha das espécies incluía a disponibilidade de estudos sobre as mesmas, bem como serem bastante conhecidas na região e de fácil identificação por parte dos estudantes. Assim, com ajuda de bibliografia especializada (Franco \& Barros, 2006; Torquato, 2006; Silva, 2008; Araújo et al., 2010), alguns exemplares foram escolhidos com a finalidade de demonstrar aspectos da Botânica relacionados aos conteúdos tratados no ensino médio. Em seguida, buscou-se informações sobre aspectos botânicos de cada espécie, para definição das atividades a serem realizadas. Foram abordados temas como interação com animais e outras plantas, morfologia vegetal, fisiologia, reprodução, mecanismos de defesa e adaptação, e as diversas utilizações pelo homem. 
Tabela 1. Espécies nativas selecionadas da literatura para intervenção na escola.

\begin{tabular}{llll}
\hline Espécie & Família & Nome vulgar & Hábito \\
\hline Anacardium occidentale L. & Anacardiaceae & Caju & Árvore \\
Attalea speciosa Mart. ex Spreng & Arecaceae & Babaçu & Árvore \\
Bromelia karatas L. & Bromeliaceae & Croatá & Erva \\
Byrsonima gardneriana A. Juss & Malpighiaceae & Murici & Arbusto \\
Caryocar coriaceum Wittm & Caryocaraceae & Pequi & Árvore \\
Copernicia prunifera (Mill.) H.E.Moore & Arecaceae & Carnaúba & Árvore \\
Hymenaea stigonocarpa Mart. ex Hayne & Fabaceae & Jatobá & Árvore \\
Lecythis pisonis Cambess & Lecythidaceae & Sapucaia & Arvore \\
Parkia platycephala Benth & Fabaceae & Faveira & Árvore \\
Platonia insignis Mart. & Clusiaceae & Bacuri & Árvore \\
\hline
\end{tabular}

Fonte: Autores.

Foram elaboradas estratégias didáticas que exploravam aspectos botânicos das plantas selecionadas (Figura 1).

Figura 1. Fluxograma com as estratégias elaboradas com base em plantas nativas pertencentes ao município de EsperantinaPI.

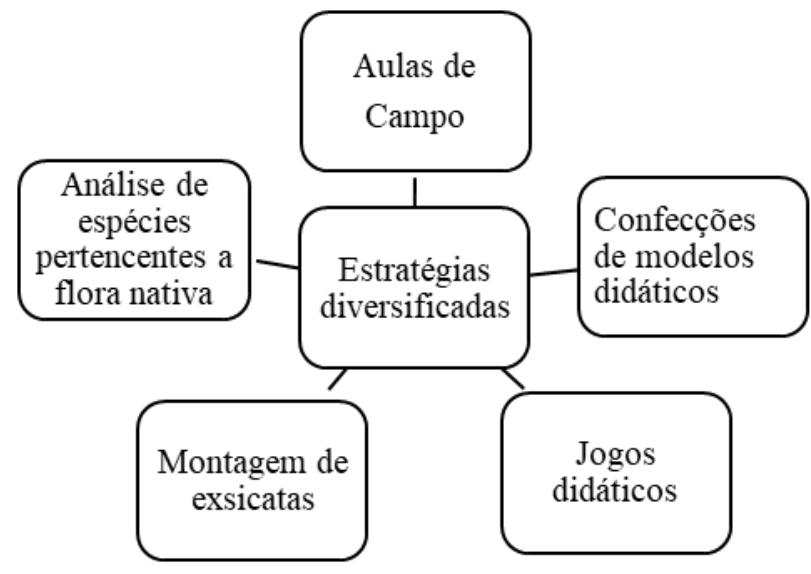

Fonte: Autores.

O projeto foi executado em três etapas:

\section{I- ETAPA}

Iniciou com a aplicação do questionário pré-teste ao grupo experimental, com abordagem quali-quantitativa dos conhecimentos dos estudantes a respeito de temas da Botânica. Estes puderam expor suas dificuldades em relação a aprendizagem, sua opinião sobre a realização de atividades diferenciadas para o ensino desse conteúdo, e quais conhecimentos já possuíam a respeito da flora nativa da região. Em seguida, foram apresentadas as plantas nativas selecionadas (Tabela 1), com informações como, nome científico, popular e utilizações pelo homem, dados que foram previamente levantados em literatura especializada. Após essa exposição foram executadas as metodologias elaboradas.

A primeira atividade foi a observação de alguns exemplares frescos das plantas, que teve por objetivo abordar a morfologia vegetal, através de exemplares de folhas, flores e frutos. Para observação da parte reprodutiva coletou-se 
exemplares das espécies que estavam na época da floração ou frutificação. Foram observadas flores frescas de Caryocar coriaceum Wittm (pequi), Platonia insignis Mart (bacuri). Parkia platycephala Benth (faveira), Hymenaea stigonocarpa Mart. ex Hayne (jatobá) e Anacardium occidentale L. (cajú). Foram colecionadas e preparadas previamente pelo professor, exsicatas com exemplares coletados de todas as plantas selecionadas, seguindo o roteiro proposto disponível na literatura (Wiggers \& Stange, 2008), para observação da morfologia e outros aspectos.

Após a apresentação desses elementos que compõem a flora nativa e algumas de suas características, foi realizada aula passeio no entorno da escola, para observar as plantas que existiam no local. Tal atividade tinha por objetivo, levar os estudantes a perceberem as plantas existentes na escola e a sua variedade. Nesta etapa, foram entregues algumas lupas de mão, para que pudessem observar todos os detalhes das plantas encontradas, pediu-se também que os mesmos coletassem flores e folhas para a observação de suas estruturas em sala.

Após o retorno para a sala, organizou-se grupos para discussão sobre os materiais coletados. Foi observado a morfologia externa das flores coletadas, com realização de cortes para observação dos verticilos florais, discutindo-se a classificação quanto a presença dos mesmos, a função das flores na reprodução e as interações que acontecem com os agentes polinizadores. Discutiu-se ainda o papel das folhas nos processos de fotossíntese, respiração e transpiração, diferenciou-se a morfologia de monocotiledônea e eudicotiledôneas analisando o que foi coletado e os materiais fornecidos. Após essa análise foi solicitado que os estudantes desenhassem e indicassem as estruturas observadas, como uma forma de assimilação do que foi estudado.

Em seguida, iniciou-se a atividade de confecção de modelos didáticos. Os participantes foram organizados em quatro grupos: anatomia foliar, morfologia foliar, frutos/sementes e flores cada grupo ficou responsável por confeccionar modelos de um determinado aspecto botânico.

Para a anatomia vegetal, foram selecionadas e impressas imagens presentes na literatura especializada que representassem a anatomia das plantas escolhidas, além de produção de lâminas no laboratório de Botânica da Universidade Estadual do Piauí, campus de Parnaíba. Neste caso, foram realizados cortes paradérmicos da folha de Anacardium occidentale L., nas faces adaxial e abaxial, bem como cortes transversais da Copernicia prunifera (Mill.) H. E. Moore e Bromelia karatas L. para observação do mesófilo foliar. Os cortes foram coloridos usando os corantes fucsina básica e azul de astra, seguindo o roteiro de aula prática para morfologia vegetal (Luque, Sousa \& Kraus, 1996). Estas lâminas tinham por objetivo a visualização no microscópio, porém a escola não possuía microscópio, então foram produzidas imagens com câmeras e apresentadas aos estudantes para que pudessem visualizar os cortes.

Foi preparado previamente todo o material que seria utilizado como inspiração para confecção dos modelos de morfologia e anatomia vegetal. Para morfologia, foram produzidos modelos de flores em biscuit de Parkia platycephala Benth e Platonia insignis Mart. que estavam em floração. As exsicatas utilizadas tinham como objetivo mostrar a importância do uso do nome científico para identificar espécies, pois o uso do nome vulgar causa muita confusão, e promover a observação da morfologia externa da folha e comparação entre as diferenças morfológicas das folhas de monocotiledôneas e eudicotiledôneas. Assim, de posse desses recursos os estudantes puderam observar e comparar os aspectos morfológicos das diversas estruturas, elaborar os modelos a partir de suas observações dos vegetais apresentadas no material fornecido. Com a realização dessa atividade buscou-se um aprofundamento nos conhecimentos sobre morfologia externa das plantas e anatomia.

Para finalizar esta etapa foi realizada a última atividade proposta. Jogos didáticos elaborados utilizando diversos aspectos das plantas nativas, tais como curiosidades, utilizações pelo homem, morfologia externa da folha, flor e fruto, classificação taxonômica, adaptações ao ambiente e fisiologia, com informações coletadas na literatura cientifica. Foram executados dois jogos, um jogo da memória que continha 20 cartas, sendo 10 cartas com fotos das plantas e 10 cartas com informações sobre essas plantas, tais como utilizações, características morfológicas, classificação e outras, assim deviam 
relacionar cada imagem a sua característica. Também se aplicou um jogo de tabuleiro que continha 20 cartas, cada uma com uma pergunta relacionada às características botânicas das plantas nativas selecionadas e um tabuleiro com casas numeradas de 1 a 30. Esta atividade tinha por objetivo que o estudante fosse capaz de reconhecer algumas das plantas da região e conhecer suas características aumentando o seu interesse pelas mesmas.

\section{II- ETAPA}

O segundo encontro com os estudantes foi a aula de campo no Parque Ecológico Cachoeira do Urubu, com saída às 7:30 da manhã, e retorno as 11:00. Para a realização desta atividade foi feito contato com um morador da região por ser conhecedor das trilhas e das plantas que lá existem para ser o guia.

O parque localiza-se a $18 \mathrm{~km}$ do município de Esperantina-PI, localizada na divisa entre os municípios de Esperantina-PI e Batalha-PI ocupando a área de 3.063 hectares, com perímetro de 6.350m (Silva, 2008), que apresenta elementos do Cerrado, Caatinga, mata ciliar e áreas de transição (Araújo et al., 2010). O local apresenta grande diversidade com o total de 27 famílias botânicas inventariadas, sendo registrado 63 espécies, com presença de árvores, arbustos, cipós e bromélias (Silva, 2008), onde os estudantes puderam observar in loco e analisar alguns espécimes da flora nativa. Esta atividade teve como objetivo a concretização do aprendizado em sala de aula sobre morfologia vegetal de flores e frutos, interação com os seres vivos do ambiente.

Foi escolhido o sistema de trabalho em duplas para facilitar a execução da atividade, e entregue a cada dupla um roteiro da aula com os objetivos, perguntas a serem respondidas sobre a vegetação observada no local, material a ser levado, e horário de ida e volta à escola. Os estudantes receberam instruções sobre a coleta de plantas e preenchimento das fichas de identificação das espécies. Os materiais coletados foram utilizados posteriormente na produção de exsicatas.

Após a finalização da trilha, montaram as prensas com o material coletado na aula passeio, organizando-o para secar em prensas de madeira, seguindo o roteiro de montagem de exsicatas e o processo de secagem propostos na literatura disponível (Wiggers \& Stange, 2008). O material coletado foi levando pelo pesquisador para ser realizada a secagem e preparação do mesmo para a confecção das exsicatas, buscou-se o nome científico de cada espécie, utilizando como norte o nome vulgar citado pelo guia e trabalhos referentes a vegetação do parque (Silva, 2008) e do município.

\section{III- ETAPA}

Neste encontro foi realizada a montagem das exsicatas com o material coletado na etapa II. Observou-se as regras de nomenclatura, conheceu-se algumas famílias de plantas da vegetação nativa, além de discutir a importância desse tipo de material para comparação e armazenamento de espécies.

Após a realização de todas essas atividades, foi aplicado o questionário pós testes com questões sobre a contribuição desse projeto para a aprendizagem, e sobre Botânica para analisar se foram adquiridos alguns conhecimentos, se foi interessante e se contribuiu para a aprendizagem.

Como encerramento do projeto foi realizada uma pequena exposição botânica na escola com todos os materiais produzidos pelos participantes, desenhos, modelos e exsicatas, onde todos puderam apresentar seus trabalhos.

\subsection{Análise de dados}

A participação do grupo controle constou em responder um questionário a respeito de sua opinião sobre o ensino de Biologia e Botânica, seus conhecimentos nessa área, dificuldades e opinião sobre utilização de práticas diversificadas usando plantas nativas como ferramenta didática para o ensino de Botânica, para efeito de comparação com grupo experimental. Para algumas questões foi atribuída uma tabela de valor, sendo 0-nenhum, 1-pouco, 2-médio e 3-muito para quantificação dos 
dados. A análise de dados dos questionários pré e pós atividades, foi realizada com a aplicação do teste $T$ student, indicado para verificação de significância estatística para amostras pareadas. A análise estatística dos dados do grupo controle, foi feita pelo teste de Kruskal-Wallis, em que se comparou os dados desde grupo com os do grupo experimental. Todas as análises estatísticas utilizaram o programa BIOESTAT 5.3.

Para citar as opiniões de estudantes mantendo o princípio do sigilo, estas foram indicadas pela letra E e um número.

\section{Resultados e Discussão}

Conforme relatado na metodologia, a primeira atividade executada foi a análise de espécies pertencentes a flora nativa da região, seguida da aula de campo no entorno da escola (Figura 2A). Percebeu-se que no entorno da escola ocorriam apenas espécies exóticas como, Psidium guajava L. (goiaba), Terminalia catappa L. (amendoeira), Azadirachta indica A. Juss (nim), Hibiscus sp. L. (hibisco), Turnera ulmifolia L. (chanana), Pimpinella anisum L. (erva doce) e Plectranthus barbatus Andrews (boldo), demonstrando que a desvalorização da vegetação nativa, não é exclusiva apenas do livro didático (Sales \& Landim, 2009), mas também do próprio ambiente escolar.

A realização dessa atividade proporcionou a percepção desta realidade, pois aulas de campo permitem um contato mais direto com o meio ambiente (Dutra \& Gülich, 2014), fazendo o estudante perceber a fauna e flora local, neste caso a ausência dessa vegetação nativa. As aulas de campo têm por objetivo buscar informação no ambiente, proporcionando uma experiência inestimável (Krasilchik, 2016).

A presença dessas espécies chamou a atenção dos estudantes, muitos acreditavam que eram nativas devido a distribuição de ocorrência em grande escala pelo país. Percebe-se essa informação por algumas afirmações, por exemplo, o E02 ao dizer "Sim, agora eu conheço um pouco mais sobre o ambiente em que convivo". O mesmo fato também foi relatado, em outras experiências sobre o uso de atividades práticas para o ensino de Botânica, em que os estudantes ficam surpresos ao descobrirem que muitas plantas que julgavam ser nativas na verdade são exóticas (Corrêa et al., 2016).

Como parte desta etapa do trabalho, também foram coletadas flores das plantas existentes no ambiente para a análise de suas estruturas. Esta atividade permitiu a interação entre o que é ensinado em sala de aula e a prática, contextualizando o assunto com o dia a dia do estudante (Corrêa et al., 2016). Utilizou-se a estratégia do desenho (Figura 2B), para promover a fixação da forma das estruturas e seus nomes, pois a atividade de ilustração torna o ensino mais concreto, proporcionando a percepção das plantas, suas características e importância (Milach et al., 2015).

$\mathrm{Na}$ mesma etapa de trabalho, realizou-se confecção de modelos didáticos, tais atividades tiveram uma avaliação positiva. O E13 afirmou o seguinte a respeito desta atividade, "Foi interessante pois praticamos o que aprendemos". Modelos didáticos concretizam a teoria e a prática (Corte, Saraiva \& Perin, 2018). A conexão é importante, tornando a aprendizagem significativa, pois há necessidade de relacionar estruturas, localizá-las, observar escalas, permitindo uma aproximação com a realidade (Matos et al., 2015).

Outra atividade que também despertou o interesse dos estudantes foram os jogos didáticos (Figura 2C), estes proporcionaram um momento de diversão durante a aula, complementando o que foi discutido na teoria. $\mathrm{O}$ uso de jogos estimula o desenvolvimento mental, psicológico, intelectual e social, mesmo que inconscientemente (Brito et al., 2016). Dessa forma, atividades divertidas facilitam a aprendizagem (Matos et al., 2015). Os resultados encontrados neste trabalho corroboram com o que afirmado pelos autores citados acima.

$\mathrm{Na}$ segunda etapa, realizou-se uma aula de campo no Parque Ecológico Cachoeira do Urubu, Esperantina-PI (Figura 2D) que proporcionou aos estudantes conhecer um pouco mais sobre a flora nativa da região, conforme é afirmado por alguns deles. Segundo o E06 "Conheci plantas nativas da região" e o E22 diz "Conheci plantas e até flores que são comuns aqui na região que não conhecia”. 
A confecção das exsicatas (Figura 2E), cujo material foi coletado no passeio ao Parque Ecológico Cachoeira do Urubu conforme descrito na metodologia, e a realização da exposição botânica (Figura $2 \mathrm{~F}$ e Figura $2 \mathrm{G}$ ), possibilitaram a visualização dos recursos naturais, e assim talvez, promovam a conscientização sobre a importância da conservação da biodiversidade brasileira, desconstruindo a ideia de que a Botânica é desinteressante (Corrêa et al., 2016), sendo isso percebido na afirmação do E06 "Pois assim passamos a conhecer e a preservar as nossas plantas". Esse tipo de atividade que explora o ambiente promove a interiorização do sentimento de preservação do ambiente, retomando a relação homem e natureza (Figueiredo, 2009; Seniciato \& Cavassan, 2009). É importante a percepção da sensação de pertencimento do meio, para que se desenvolva na consciência o instinto de conservação dos ambientes naturais.

Com o objetivo de verificar se a execução das atividades foi capaz de influenciar o interesse dos estudantes pela Botânica, foi questionado aos mesmos se gostavam da disciplina. A maioria afirmou gostar do tema, e o interesse cresceu após a realização das atividades de intervenção. É interessante observar que alguns estudantes que afirmaram não gostar mudaram de opinião, como é o caso do E12, que antes afirmava "Porque não sou muito voltado as plantas nesses últimos tempos", mudou seu pensamento após a atividade, dizendo "Porque as plantas são importantes". Acredita-se que esta mudança resulte das atividades executadas, em que alguns passaram a ver com mais interesse. Pois quando se realiza atividades práticas que envolvam o cotidiano, se permite a percepção de que a Botânica faz parte da sua vida (Amadeu \& Maciel, 2014).

Para verificar se um dos objetivos foi alcançado, o de minimizar a "cegueira botânica" citado por alguns autores (Wandersee \& Schussler, 2001), foi questionado aos estudantes a respeito de sua afinidade pela disciplina, e se houve mudanças a respeito da mesma. Como pode ser observado houve um aumento na média desse quesito antes e depois das atividades (Tabela 2), acredita-se que alguns estudantes mudaram sua percepção das plantas e passaram a ver o estudo com uma nova perspectiva, já que houve uma diferença significativa, como revela o teste $T$ student, comparando-se o antes e depois da realização das atividades, sobre a afinidade com a Botânica. Percebe-se que antes das atividades a média de valores estabelecida foi entre pouco e nenhum, porém após as atividades a média de valores estabelecidos aumentou para médio e muito. Ao comparar a média do grupo controle com a média do grupo experimental, observa-se que entre os três questionários, a maior média está no item após a atividade, sugerindo que a atividade surtiu o efeito desejado.

Figura 2. Atividades realizadas: A- Aula de campo entorno da escola: B-Desenhos de estruturas observadas, C- Execução de jogo didático; D- Aula de campo ao Parque Ecológico Cachoeira do Urubu; E-Exsicata de Copaifera martii Hayne (podói); FExposição do painel no pátio da escola; G- Exposição das exsicatas;

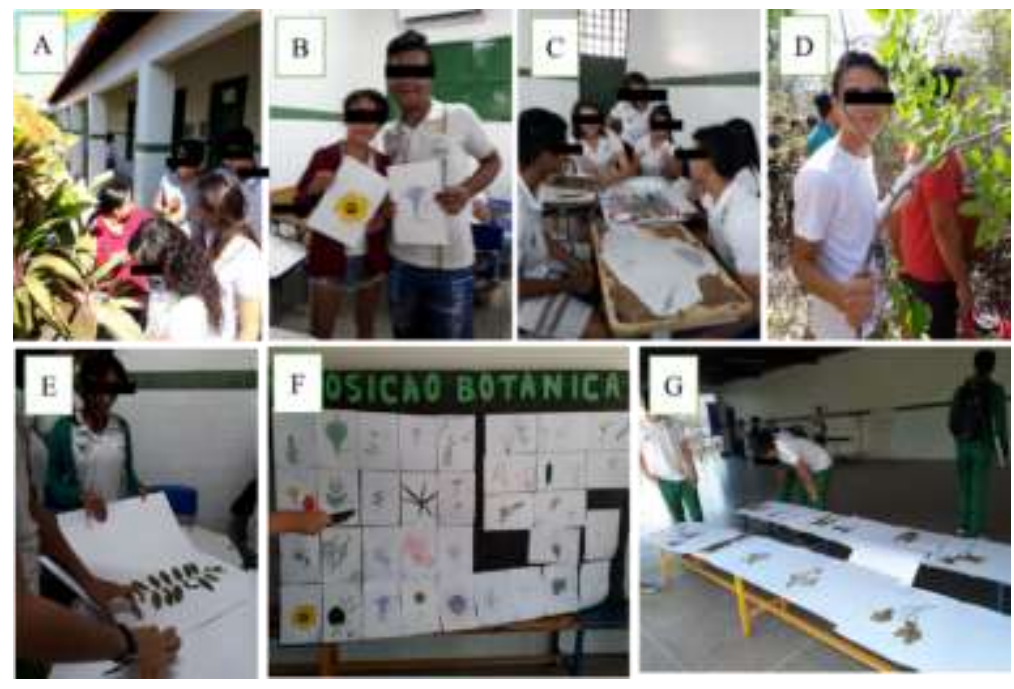

Fonte: Autores. 
Ao analisar as justificativas dadas pelos estudantes sobre o porquê consideram importante, $66,1 \%$ se referiram a diversos aspectos como ter conhecimentos sobre o meio ambiente, para a natureza ou seu uso medicinal. Um pequeno percentual (1,6\%), disse que era importante para concursos e vestibulares, enquanto 32,3\% não justificaram sua opinião.

Tabela 2. Média da afinidade dos estudantes com a Botânica antes e depois das atividades de intervenção e p-valor calculado pelo teste $T$ student e a média do grupo controle.

\begin{tabular}{llll}
\hline & Antes & Depois & Grupo controle \\
\hline Indivíduos & 45 & 45 & 39 \\
Média & 1,3778 & 2,3778 & 1,15 \\
Desvio Padrão & 0,6498 & 0,4903 & \\
Erro Padrão & 0,0969 & 0,0731 & \\
Desv. Padrão da Diferença & 0,7977 & --- & \\
Erro Padrão da Diferença & 0,1189 & --- & \\
Média das diferenças & -1 & --- & \\
(t)= & $-8,4092$ & --- & \\
Graus de Liberdade & 44 & --- & \\
(p) unilateral = & $<0,0001$ & --- & \\
\hline
\end{tabular}

Fonte: Autores.

Para verificar se as atividades realizadas promoveram a facilitação da aprendizagem e aquisição de conhecimentos, os estudantes foram questionados a respeito de sua consideração sobre seu nível de conhecimento em alguns conteúdos da disciplina. Essa avaliação é realizada de forma subjetiva, já que revela a opinião dos estudantes a respeito dos conhecimentos adquiridos. Assim, dentre as áreas sugeridas, houve um aumento nas afirmações, ou seja, muitos disseram ter aprendido mais sobre as mesmas. Destas, a flora nativa foi a que apresentou o maior aumento, revelando que muitos passaram a conhecer mais sobre a vegetação local. Com esses resultados, entende-se a flora nativa como ferramenta didática que pode incentivar e aumentar a aprendizagem de Botânica. Para cada conteúdo questionado houve uma variação significativa ( $\mathrm{p}$-valor $<0,0001$ ) após a intervenção (Tabela 3).

Tabela 3. Médias sobre o conhecimento dos estudantes sobre cada aspecto da Botânica.

\begin{tabular}{lccll}
\hline & $\begin{array}{c}\text { Antes } \\
(\mathbf{1})\end{array}$ & $\begin{array}{c}\text { Depois } \\
(\mathbf{2})\end{array}$ & Variância & P-valor (teste T) \\
& 1,36 & 2,22 & 1,36 & $<0,0001$ \\
\hline Classificação & 1,04 & 2,04 & 1,04 & $<0,0001$ \\
Morfologia & 1,58 & 2,42 & 1,58 & $<0,0001$ \\
Reprodução & 1,04 & 2,13 & 1,04 & $<0,0001$ \\
Tecidos Vegetais & 0,93 & 1,91 & 0,93 & $<0,0001$ \\
Fisiologia vegetal & 1,55 & 2,66 & 1,55 & $<0,0001$ \\
Plantas nativas & & & & \\
\hline
\end{tabular}

Fonte: Autores.

A aquisição de conhecimento que apresentou maior variação foi sobre plantas nativas, ou seja, os participantes em média consideraram ter mais conhecimentos sobre esse aspecto depois da realização das atividades. Isso revela que pouco se 
explora nas salas de aulas, espécies que compõem a flora nativa em que a comunidade escolar está inserida, criando um distanciamento entre o que é ensinado e a vivência dos estudantes.

Existe uma descontextualização entre os ecossistemas mostrados nos livros didáticos e a flora nativa do Nordeste (Sales \& Landim, 2009), o estudo de Botânica é realizado sem alusão ao cotidiano do estudante e suas vivências (Figueiredo, 2009). Dessa forma, falta estabelecer mais conexões entre o ensino e o ambiente do estudante para que a aprendizagem seja facilitada e mais conhecimentos sejam adquiridos.

Ao comparar as médias obtidas do grupo controle, com as médias de antes e depois das atividades do grupo experimental, através do teste Kruskal-Wallis (Tabela 4), observa-se uma variação significativa entre as médias desses grupos. Para analisar os dados da tabela, deve se comparar o $\mathrm{Z}$ calculado e o $\mathrm{Z}$ crítico, ao observar esses valores obtidos pelo grupo experimental, antes das atividades, com o grupo controle, percebe-se que não há diferença significativa, isso deve-se ao fato que ambos não participaram de nenhuma atividade direcionada ao ensino de Botânica, e por isso apresentam o mesmo juízo de valor. Porém ao comparar os valores do grupo experimental, após as atividades, com o grupo controle, revela-se uma diferença significativa, o que permite concluir que, a realização das atividades aumentou o julgamento dos participantes a respeito dos conhecimentos que os mesmos possuem em alguns conteúdos da Botânica. Questionou-se também a respeito dos conhecimentos sobre as plantas nativas da região, boa parte afirmou que tem conhecimento médio sobre as plantas nativas após a realização das atividades.

Tabela 4. Análise estatística comparando as médias dos grupos sobre a aquisição de conhecimentos em aspectos da Botânica.

\begin{tabular}{lllll}
\hline $\begin{array}{l}\text { Comparações (método de } \\
\text { Dunn) }\end{array}$ & Dif. Postos & Z calculado & Z Crítico & $\begin{array}{l}\text { P-valor (Kruskal- } \\
\text { Wallis) 0.0034 }\end{array}$ \\
\hline Antes e grupo controle & 0,1667 & 0,0541 & 2,394 & Não significativo \\
Depois e grupo controle & 9,0833 & 2,947 & 2,394 & $<0,05$ \\
\hline
\end{tabular}

Fonte: Autores.

Para verificar se essas metodologias foram eficientes, foi perguntado aos estudantes do grupo experimental, se acharam interessante e se essas atividades haviam contribuído com a aprendizagem. Considerou-se que as atividades aplicadas tiveram uma contribuição média para a aprendizagem, esse resultado foi obtido após se calcular a média das médias das atividades realizadas, obtendo-se o valor 2,03, que segundo a tabela estabelecida seria o médio (Tabela 5).

Dentre as atividades, a que obteve maior média foi a aula no entorno da escola, obtendo média 2,08, sugerindo que essa teria sido mais interessante e contribuiu mais com a aprendizagem. Os resultados deste trabalho corroboram com outros autores, ao afirmarem que a realização de aulas de campo é uma forma do professor proporcionar ao estudante um contato mais direto com o meio ambiente, fazendo perceber a fauna e a flora local (Figueiredo, 2009; Freitas et al, 2012; Dutra \& Güllich, 2014). Outros afirmam que tal atividade funciona com um combustível para dinamizar e estabelecer uma nova visão da relação homem/natureza (Seniciato \& Cavassan, 2009). É possível que tenha sido essa a razão pela qual essa atividade tenha obtido uma média maior. 
Tabela 5. Consideração dos estudantes sobre a contribuição das atividades para a aprendizagem. A- Aula de campo no entorno da escola; B- Aula de campo a cachoeira; C- Modelos didáticos; D- Jogos didáticos; E- Atividade tornou a botânica mais interessante; F- A exploração da flora nativa contribui para aprendizagem. Abreviações: fi: frequência simples; Fi: frequência relativa.

\begin{tabular}{lllllllllllll}
\hline & $\mathbf{A}$ & & $\mathbf{B}$ & & $\mathbf{C}$ & & $\mathbf{D}$ & & $\mathbf{E}$ & & $\mathbf{F}$ & \\
Valor & $\mathbf{F i}$ & $\mathbf{F i}$ & $\mathbf{f i}$ & $\mathbf{F i}$ & $\mathbf{f i}$ & $\mathbf{F i}$ & $\mathbf{f i}$ & $\mathbf{F i}$ & $\mathbf{f i}$ & $\mathbf{F i}$ & $\mathbf{f i}$ & $\mathbf{F i}$ \\
\hline 0 & 0 & $0 \%$ & 0 & 0 & 0 & $0 \%$ & 2 & $4,44 \%$ & 0 & $0 \%$ & 0 & $0 \%$ \\
1 & 5 & $11,11 \%$ & 4 & $8,89 \%$ & 11 & $24,44 \%$ & 5 & $11,11 \%$ & 5 & $11,11 \%$ & 7 & $15,56 \%$ \\
2 & 31 & $68,89 \%$ & 30 & $66,67 \%$ & 25 & $55,56 \%$ & 31 & $68,89 \%$ & 32 & $71,11 \%$ & 31 & $68,88 \%$ \\
3 & 9 & $20 \%$ & 11 & $24,44 \%$ & 9 & $20 \%$ & 7 & $15,56 \%$ & 8 & $17,78 \%$ & 7 & $15,56 \%$ \\
Média & & 2,08 & & 2,15 & & 1,95 & & 1,95 & & 2,06 & 2 \\
\hline
\end{tabular}

Fonte: Autores.

Boa parte dos estudantes afirmaram que as atividades eram interessantes e que contribuíram com a aprendizagem. Esse aspecto também fica evidenciado pela afirmação do E01 "Contribui pelo fato de usar plantas que vemos diariamente". Porém duas atividades obtiveram menor média, os jogos didáticos e confecção de modelos didáticos. É possível que os resultados observados em relação a aplicação de jogos didáticos, resultem do fato que muitos participantes ficaram entusiasmados e muitas vezes perderam o foco, fornecendo esse resultado para essa atividade. Na literatura sugere-se que a aplicação de jogos didáticos não seja feita por uma única pessoa, para evitar bagunça e manter a ordem para assim tenha mais sucesso (Brito et al., 2016). Os estudantes também expressaram suas opiniões a respeito dessa atividade. O E01 diz que "Motiva de maneira que estimula o conhecimento que temos em uma dinâmica divertida", O E15 afirma que "Foi maravilhoso é uma forma de aprender jogando".

Como se percebe através das opiniões de alguns estudantes, a atividade foi interessante e contribuiu para aprendizagem, porém também recebeu críticas conforme a opinião do E06 ao afirmar "Joguei pouco", indo ao encontro sugerido na literatura, em que o uso de jogos didáticos pode causar certo alvoroço (Brito et al., 2016) e assim, alguns acabam não participando conforme o desejado. Entretanto, mesmo com esse resultado essa atividade ainda é interessante como metodologia de ensino.

Apesar da atividade de construção de modelos ter sido uma das que obteve menor média, ao serem questionados sobre a mesma, suas opiniões foram bastante favoráveis. O E01 disse que "Foi interessante reconhecer plantas nativas em imagens aproximadas e direcionadas especificamente ao que queremos". O E29 disse que "Sim, pois ficou mais fácil aprender sobre Botânica". A utilização de modelos didáticos permite a associação do tamanho, volume e localização das estruturas, permitindo uma aproximação da realidade e possibilitam uma aprendizagem significativa (Matos et al., 2015; Evangelista \& Barros, 2018). Alguns autores reforçam essa ideia, ao afirmarem que atividades que utilizam modelos didáticos são fascinantes e possibilitam a concretização de informações apresentadas por meio de aulas teórica, além da visualização de conceitos através de diversos materiais (Dutra \& Gülich, 2014; Krasilchik, 2016; Nascimento et al., 2017), estas afirmações são ratificadas com os resultados obtidos e opiniões emitidas pelos estudantes.

\section{Considerações Finais}

Este trabalho de pesquisa teve como objetivo apresentar mais opções de metodologias que busquem facilitar a aprendizagem de Botânica, com o uso da flora nativa da região em que a escola está inserida, de forma a valorizar a realidade 
do estudante e seu cotidiano, reduzindo a "cegueira botânica". Foram realizadas atividades diversificadas que exploravam aspectos de algumas plantas pertencentes a vegetação da região. As atividades executadas apresentaram-se satisfatórias quanto ao seu propósito, pois muitos participantes expressaram ter aprendido mais sobre a disciplina, conforme demonstram dados estatísticos. Grande parte relatou o interesse pelas atividades e que contribuíram com sua aprendizagem, além de passarem a conhecer algumas plantas nativas.

Porém, a respeito da utilização das estratégias sugeridas foram identificados alguns obstáculos, existe pouco material disponível para o ensino da disciplina envolvendo a flora nativa, principalmente do Nordeste, os próprios livros didáticos são carentes dessas informações. Então, cabe ao professor buscar e elaborar seus materiais e metodologias.

Acredita-se que a análise realizada com a literatura disponível e pelos resultados obtidos neste trabalho, a metodologia é viável e facilitadora. Seria interessante que no futuro mais estudos sejam desenvolvidos com essa abordagem, buscando mais estratégias que explorem a flora nativa como recurso didático eficiente no ensino de Botânica.

Pensando na viabilidade do uso da flora nativa como ferramenta de ensino, muitas vertentes podem ser exploradas, como por exemplo, trabalhos incluindo etnobotânica, que associa conhecimento da comunidade sobre o uso e manipulação de diversas plantas, ou a construção de coleções botânicas com plantas nativas, ou ainda aulas de campo em ambientes naturais para exploração da vegetação local. Esse é um campo que pode ser explorado de diversas formas promovendo a valorização dos ecossistemas locais e conscientização dos estudantes sobre a importância dos mesmos.

\section{Agradecimentos}

Os autores agradecem ao PROFBIO, à CAPES, à UESPI e a escola participante da pesquisa.

\section{Referências}

Amadeu, S. O. \& Maciel, M. D. (2014). A dificuldade dos professores de educação básica em implantar o ensino prático de botânica. Rev. Produção Discente em Educ. Matemática, 3(2), 225-235. https://revistas.pucsp.br/ pdemat/article/view/21269/15549

Araújo, J. L. L. et al. (2010). Atlas Escolar Piauí Geo-histórico e Cultural. Grafset.

Arrais, M. G. M.; Sousa, G. M. \& Masrua, M, L. (2014). O ensino de Botânica: investigando dificuldades na prática docente. Revista SBEnBio, (7), 54095418. http://www.sbenbio.org.br/wordpress/wp-content/uploads/2014/11/R0115-2.pdf.

Brasil (1998). Resolução CEB $n^{o}$ 3, de 26 de junho de 1998. Institui as Diretrizes Curriculares Nacionais para o Ensino Médio. http://portal.mec.gov.br/cne/arquivos/pdf/rceb03_98.pdf

Brito, L. P, de. et al. (2016). O uso de jogos didáticos e o ensino de biologia: aprendendo botânica. In. III Congresso Nacional de Educação. Natal. http://www.editorarealize.com.br/revistas/conedu/trabalhos/trabalho_ev056_md4_sa18_id487_150 82016122237.pdf

Castro, V. M. (1999). Aspectos de Esperantina. Esperantina-PI: Prefeitura Municipal de Esperantina.

Cepro, Fundação. (2004). Diagnóstico e Diretrizes para o Setor Mineral do Estado do Piauí. http:// www.cepro.pi.gov.br/ download/200804/CEPRO16_6695f7c23c.pdf

Corrêa, B. J. S. et al. (2016). Aprendendo Botânica no ensino médio por meio de atividades práticas. Revista da SBEnbio, 6 (9), $4314-4324$.

Corte, V. B.; Saraiva, F. G.; Perin, I. T. D. A. L. (2018). Modelos didáticos como estratégia investigativa e colaborativa para o ensino de Botânica. Revista Pedagógica, 20(44), 172- 2018. https://bell.unochapeco.edu.br/revistas/index.php/pedagogica/article/view/3871/2520

Dutra, A. P. \& Güllich, R. I. C. (2014). A Botânica e suas metodologias de ensino. Revista SBEnBio, (7), 493-503. https://sbenbio.org.br/wpcontent/uploads/edicoes/revista_sbenbio_n7.pdf

Evangelista, C. de S. \& Barros, M. A. de M. (2018). Produção de modelos didáticos: uma possibilidade facilitadora no ensino de botânica. Revista Vivências de Ensino de Ciências, v. 2, 69-75. https://periodicos.ufpe.br/revistas/vivencias/article/view/238689/30427

Farias, R. R. S \& Castro, A. A. J. F. (2004). Fitossociologia de trechos da vegetação do Complexo de Campo Maior, PI, Brasil. Acta Botânica Brasilica, 18 (4), 949-963. Acesso em 02 feb., 2018, http://www.scielo.br/pdf/abb/v18n4/23229.pdf

Figueiredo, J. A. (2009). O ensino de Botânica em uma abordagem ciência, tecnologia e sociedade: propostas de atividades didáticas para o estudo das flores nos cursos de Ciências Biológicas. (Dissertação de Mestrado ). Pontifícia Universidade Católica de Minas. Belo Horizonte. 
Franco, E. A. P; Barros, R. F. M. (2006) Uso e diversidade de plantas medicinais no Quilombo Olho D’água dos Pires, Esperantina, Piauí. Revista Brasileira de Plantas Medicinais, 8(3), 78-88. http://www.sbpmed.org.br/download/issn_06_2/artigo12_v8_n3.pdf

Freitas, D. et. al. (2012). Uma abordagem interdisciplinar da Botânica no Ensino Médio. IESDE Brasil.

Gerhart, T. E. ; Ramos, I . C. A; Riquinho, D. L., \& Santos, D. L. (2009) Estrutura do projeto de pesquisa.. In: Gerhart, T. E \& Silveira, D. T (Orgs). Métodos de Pesquisa. Porto Alegre: Editora da UFRGS. 65-88. http://www.ufrgs.br/cursopgdr/downloadsSerie/derad005.pdf.

Krasilchik, M. (2016). Prática de ensino de Biologia. EDUSP.

Luque, R.; Sousa, H. C. de, \& Kraus, J. E. (1996). Métodos de coloração de Roeser (1972): modificado - e Kropp (1972) visando a substituição do azul de astra por azul de alcião 8GS ou 8GX. Acta Botanica Brasilica, 10(2), 199-212. http://www.scielo.br/pdf/abb/v10n2/v10n2a01.pdf

Macedo, M. et al. (2012). Concepções de professores de Biologia do ensino médio sobre o ensinoaprendizagem de Botânica. In: Encontro Ibero-Americano Sobre Investigação Em Ensino De Ciências, 4, Anais...Porto alegre: UFRGS, 2012. p. 387-401. http://www.if.ufrgs.br/ienci/uploaded/ ATA_EIBIEC_IV.pdf.

Matos, G. M. A. et al. (2015). Recursos didáticos para o ensino de botânica: uma avaliação das produções de estudantes em Universidade Sergipana. Holos, 5 , 213-230. http://www2.ifrn.edu.br/ojs/index.php/HOLOS/article/view/1724/1157

Milach, E. M.; et al (2015). A ilustração científica como uma ferramenta didática no ensino de Botânica. Acta Scientiae, 17(3), 672-683. http://www.periodicos.ulbra.br/index.php/acta/article/view/1115/1312

Nascimento, B. M. et al. (2017). Propostas pedagógicas para o ensino de Botânica nas aulas de ciências : diminuindo entraves. Reec.Uvigo. Es, 16(2), 298315. http://reec.uvigo.es/volumenes/volumen16/REEC_16_2_7_ex1120.pdf

Peixoto, A. L.; Luz, J. R. P. \& Brito, M. A. de (org). (2016). Conhecendo a biodiversidade. MCTIC, CNPq, PPbio. https://ppbio.inpa.gov.br/sites /default/files/conhecendo_a_biodiversidade_livro.pdf

Sales, A. B. S. \& Landim, M. F. (2009). Análise da abordagem da flora nativa em livros didáticos de biologia usados em escolas de Aracaju - SE. Experiências em Ensino Ciências-UFMT, 4(3), 17-29. http://if.ufmt.br/eenci/artigos/Artigo_ID86/v4_n3_a 2009.pdf

Seniciato, T. \& Cavassan. (2009). O. Aulas de campo em ambientes naturais e aprendizagem em ciências: um estudo com alunos do ensino fundamental. Ciência \& Educação, 10(1), 133-147. http:// www.scielo.br/pdf/ciedu/v10n1/10.pdf"

Silva, B. I. A.et al. (2019). O saber botânico através da seringueira: como conservar o que não conhecemos? Biota Amazônia, 9(2), 11-15. https://periodicos.unifap.br /index.php/biota/article/download/4439/v9n2p11-15.pdf

Silva, C. G. B. (2008). Estado de conservação dos fragmentos florestais na Área de Proteção Ambiental-APA estadual Cachoeira do Urubu (PI) e avaliação de indicadores para monitoramento ambiental. (Dissertação de Mestrado). Universidade Federal do Piauí, Teresina-PI.

Silva, L. S. A. da.; Cândido, S. A. \& Lima, L. R de (2018). Botânica no ensino médio e o uso de metodologias alternativas no seu processo de ensinoaprendizagem. In: V Congresso Nacional De Educação, 5, 2018, [Olinda-PE]. Anais ...[S.I]: Editora Realize. 2018. 12p. http://www.editorarealize.com.br/revistas/conedu/trabalhos/trabalho_ev117_md1_sa16_id10121_17092018223428.pdf

Soares, J. P. R. (2020). A prática no ensino de botânica: o que dizem os principais congressos?. Revista Cruzeiro do Sul. REnCiMa, 11(6), 73-93, http://revistapos.cruzeirodosul.edu.br/index.php/rencima/article/view/2360/1361

Souza, K. R., \& Kerbauy, M. T. M. (2017). Abordagem quanti-qualitativa: superação da dicotoamia quantitativa-qualitativa na pesquisa em educação. Educação e filosofia, 31(61), 21-44. https://doi.org/10.14393/REVEDFIL.issn.0102-6801.v31n61a2017-p21a44

Torquato, T. G. M. (2006). Potencial da vegetação melitófila e abelhas associadas da área Olho d'água dos pires, Esperantina, Piauí, Brasil. (Dissertação de Mestrado).Universidade Federal do Píaui, Teresina-PI. http://livros01.livrosgratis.com.br/cp114386.pdf

Ursi, S. et al. (2018). Ensino de Botânica: Conhecimento e encantamento na educação científica. Estudos Avançados, 32(94), 7-.24. http://www.scielo.br/pdf/ea/v32n94/0103-4014-ea-32-94-00007.pdf

Wandersee, J.H. \& Schussler, E. (2001) Toward a theory of plant blindness. Plant Science Bulletin, 47(1), 2-9. https://botany.org/bsa/psb/2001/psb47-1.pdf

Wiggers, I. \& Stange, C. E. B. (2008). Manual De Instruções Para E Herborização De Material. Laranjeiras do Sul, PR: Programa de Desenvolvimento Educacional - SEED - PR, p.45. http://www.diaadiaeducacao.pr.gov.br/portals /pde/arquivos/733-2.pdf 